\title{
Variação de registro e orações relativas na passagem do texto oralao escrito: relato de experiência didática
}

Filomena Varejão ${ }^{1}$

Resumo: Este artigo apresenta experiência didática a partir da técnica de retextualização como metodologia de ensino/aprendizagem da escrita de entrevistas (semi)formais capturadas em áudio. $\mathrm{O}$ processo resultou em reflexões didaticamente orientadassobre certas estruturas variáveis na morfossintaxe do português brasileiro - especificamente, sobre estratégias de relativização - e sobre a natureza da fala e da escrita como modalidades graduais, embasando-nos principalmente nos postulados de Marcuschi $(1986,2010)$ para a realização das reflexões aqui propostas sobre a relação fala-escrita.

Palavras-chave: Entrevistas. Retextualização. Variação. Sentenças relativas.

\begin{abstract}
This paper presents didactic experience based on the technique of retextualization as methodology of teaching/learning writing of (semi)formal interviews captured in audio. The process resulted in didactically oriented reflections on certain variable structures in the Brazilian Portuguese morphosyntax - specifically, on relativization strategies - and on the nature of speech and writing as gradual modalities, basing ourselves especially on Marcuschi's (1986, 2010) postulations to develop the discussion proposed in this paper regarding the relation between speech and writing.
\end{abstract}

Keywords: Interviews. Retextualization. Variation. Relative sentences.

Resumen: Este artículo presenta experiencia didáctica a partir de la técnica de retextualización como metodología de enseñanza/aprendizaje de la escritura de entrevistas (semi)formales capturadas en audio. El proceso resultó en reflexiones didácticamente orientadas sobre ciertas estructuras variables en la morfosintaxis del portugués brasileño - específicamente, sobre estrategias de relativización - y sobre la naturaleza del habla y de la escritura como modalidades graduales, con

\footnotetext{
${ }_{1}$ Professora Associada I do Setor de Língua Portuguesa da Faculdade de Letras da Universidade Federal do Rio de Janeiro (UFRJ), integrando o corpo docente dos cursos da Graduação e da Pós-Graduação do Programa de Mestrado Profissional (Profletras). Possui Mestrado e Doutorado pela UFRJ.
}

Este artigo está licenciado sob forma de uma licença Creative Commons Atribuição 4.0 Internacional,

que permite uso irrestrito, distribuição e reprodução em qualquer meio, desde que a publicação

original seja corretamente citada. https://creativecommons.org/licenses/by/4.0/deed.pt BR. 
base especialmente en los postulados de Marcuschi $(1986,2010)$ para las reflexiones aquí propuestas acerca de la relación habla-escrita.

Palabras clave:Entrevistas. Retextualización. Variación. Sentencias relativas.

\section{Introdução}

A partir da publicação dos Parâmetros Curriculares Nacionais (PCNs), no final dos anos 1990, defende-se oficialmente que o ensino de língua portuguesa deve ter como referencial básico o estudo de ampla gama de gêneros textuais, a partir dos quais os aprendizes possam observar o funcionamento da língua em usos situados, refletir sobre o lugar da linguagem nas interações reais e ampliar seu próprio repertório linguístico.Entre as metas traçadas para a tarefa de ensino de linguagens, o documento é claro ao dizer que "desenvolver o domínio da expressão oral e escrita em situações de uso público da linguagem, levando em conta a situação de produção social e material do texto" (BRASIL, 1998, p. 49) é objetivo a ser assegurado.

Sugere-se, desse modo, queo trabalho pedagógicoprecisa recobrir, entre outros objetos,o exercício reflexivo e práticoacerca de aspectos linguísticos (incluindo os gramaticais) inserido nos processos de leitura e de produção de textos orais e escritos. No entanto, no que diz respeito ao trabalho com a modalidade oral, hápoucasreferências críticas disponíveis aos professores. O tratamento da oralidade nos materiais didáticos quase sempre se reduz à comparação entre fala e escrita, objetivando marcar, sobretudo, a distância entre o dizer (sempre) informal e o escrever (sempre) formal, como observa Bagno (2010).Em consequência, ao abordar textos falados e escritos, o ensino básicotende a reproduzira falsa dicotomia informalidade versus formalidade e acaba 
por fortalecer mitos preconceituosos quanto aos usos variáveis da língua, excluindo uma riqueza de possibilidades no desenvolvimento da competência comunicativa.

Não se desconhece o fato de que é função quase exclusiva da instituição escolar o desenvolvimento de habilidades de leitura e de escrita, mas é preciso ir além e reconhecer que a escola é "o lugar privilegiado de vivência de língua materna: língua falada e língua escrita, língua-padrão e não padrão, nunca como pares opositivos, ou como atividades em competição" (NEVES, 2015, p. 90). No entanto, no que tange ao trabalho com a oralidade, muitas questões estão em aberto e carecem de respostas que orientem a tarefa pedagógica. Que fala deve ser objeto de ensino? O que os aprendizes devem ser levados a observar? Como sistematizar a abordagem do oral? Que instrumentos teóricos utilizar?

Neste artigo, descreve-se parte de experiência didática que principia na observação do oral visando chegar à consciência sobre a escrita monitorada. A proposta parte dos exercícios de escuta, transcodificação e análise de entrevistas gravadas em áudio e vídeo e chega à adaptação para o formato escrito, mediado pelas reflexões fundamentadas em investigações científicas acerca de fenômenos morfossintáticos variáveis na escrita do português brasileiro (PB). Da diversidade de objetos que o trabalho com retextualizações contempla, aqui se trata da observação refletida sobre a produção de sentenças relativas/orações adjetivas.

O planejamento do conjunto das atividades se valeu de contribuições da Análise da Conversação (MARCUSCHI, 1986), que 
ancorou as técnicas de transcrição do texto oral, e das contribuições diretas ou indiretas da Sociolinguística variacionista, sobretudo os trabalhos de Correa (1998); Kato (1999); Castilho (2003); Duarte e Serra (2015), Bortoni-Ricardo (2004), que fundamentaram as reflexões sobregramáticas do português; variação morfossintática e variação no contínuo estilístico. Como subsidiário ao processamento e observação dos textos orais e sua respectiva forma escrita, foi adotado o modelo de retextualização proposto por Marcuschi (2010).

O trabalho, desenvolvido com alunos ingressantes de graduação em Comunicação Social, permitiu não apenas a observação e análise do funcionamento da fala, mas também possibilitou ampliar o grau de consciência dos estudantes a respeito das gramáticas da fala e da escrita (KATO, 1999), emdiferentes registros do gradiente estilístico (BORTONI-RICARDO, 2004). Espera-se que este relato possa oferecer caminhos para ampliar reflexões sobre o trabalho com o oral na sala de aula de língua portuguesa.

Para melhor exposição, este artigo se estrutura da seguinte forma: a primeira parte recupera discussões teóricas em torno das gramáticas dos brasileiros e das modalidades oral e escrita da língua; em seguida, trata-se do processo de retextualização, da metodologia da atividade didática e dos resultados encontrados; e, por fim, apresentam-se as conclusões deste artigo.

\section{Concepções sobre fala escrita e escolarização}


Como lembra Marcuschi (2010, p. 19), é indiscutível que a escrita se tornou uma tecnologia indispensável à vida em sociedade e chega, hoje, a constituir a forma mais prestigiosa de interação entre as pessoas. Os indivíduos tomam posse desse bem social por meio de processos de aprendizagem que incluem, em alguma medida, estratégias metodológicas mais ou menos sofisticadas. A fala, no entanto, é naturalmente adquirida e não depende de aparatos técnicos para que as pessoasdela se apropriem. Desse modo, embora ambas ocupem diferentes dimensões no processo de apropriação de usos da língua, isso não significa, e esse parece ser o entendimento de documentos como os PCN, que ao oral caiba espaço secundário entre os objetos da educação institucionalizada. Koch (1997) considera, por exemplo, que as interferências do oral no escrito são importantes pistas a serem observadas pelo alfabetizador no planejamento do processo de aprendizagem da escrita. Na mesma linha de raciocínio, Castilho (2003, p. 13) argumenta que, se o ensino "se concentrasse mais na reflexão sobre a língua que falamos, [...] logo se descobriria a importância da língua falada, mesmo para a aquisição da língua escrita”.Pesquisas recentes, como, por exemplo, as de Araújo-Chiuchi (2011) investigam a heterogeneidade constitutiva dos textos escritos e indicam a interferência do alto grau de interação entrefala eescritano processo deaprendizagem do emprego de sinais de pontuação.

Ademais, se o objetivo oficialmente proposto ao ensino básico está centrado nos usos sociais da linguagem, o currículo escolar não pode ignorar a variação linguística, marcadamente a variação oral/escrito, conforme postulam as mais coerentes reflexões sobre o 
papel da Sociolinguística no campo do ensino². Como propõem Duarte \& Serra (2015, p. 32), observar "diferenças entre a gramática da fala, adquirida como L1, e a gramática da escrita brasileira, aprendida através do processo de letramento" traz importantes contribuições à aprendizagem de produção textual. Examinar aspectos da gramática da fala vernacular e da gramática da escrita letrada pode se revelar valioso instrumento pedagógico, pois permite a professores e aprendizes mais precisão na abordagem dos pontos em que se verifica maior distância entre as duas modalidades. Em vista dessas considerações, defende-se o papel de centralidade do oral no processo de ensino/aprendizagem.

\section{Gramáticas em interação e orações relativas}

No processo escolar de desenvolvimento das habilidades de uso das estruturas linguísticas, Kato (1999) faz importante distinção entre o saber inconsciente internalizado pelo aluno e o saber metalinguístico que vai ser desenvolvido ao longo do letramento.

Considerando que a gramática do Português Europeu (PE) serviu de baseà aproximada codificação da língua padrão escritapara o Português Brasileiro (PB) e que a gramática da fala brasileira atual abriga resultados de processos sóciohistóricos de variação e mudança, é razoável supor haver interação entre a gramática que serve ao processo de ensino na escola (supostamente baseada naquela codificação aproximada) e a gramática vernacular, que o aluno domina já na primeira infância. Segundo a autora, a fala pré-escolarização assume contornos inovadores, que entram em interação com as formas mais conservadoras praticadas

\footnotetext{
2 A esse respeito, recomenda-se a leitura de VIEIRA, S. R. Sociolinguística e ensino de português: para uma pedagogia da variação linguística. In: TAVARES, M. A.; MARTINS, M. A. (Orgs.) Contribuições da Sociolinguística e da Linguística Histórica para o ensino de língua portuguesa. Coleção Ciências da Linguagem Aplicadas ao Ensino, volume V. Natal: EDUFRN, 2013. p. 53-90.
} 
na escola e resultariam numa escrita e numa fala mais conservadora, isto é,nas gramáticas do indivíduo letrado. Esquematicamente, Kato (1999, p. 203-204) apresenta o processo da seguinte forma:

$\begin{array}{llll}\text { FALA }^{1} & >\text { ESCRITA }^{1} & >\text { ESCRITA }^{2} & >\text { FALA }^{2} \\ \text { pré-escrita } & \text { transcrição da fala } & \text { neutra em relação } & \text { filtrada pela tecnologia } \\ & \text { do sujeito } & \text { às falas } & \text { da escrita }\end{array}$

Processo que resulta numa interação entre gramática vernacular e regras da escritainstitucionalizada pela escolarização, como demonstra o esquema:

$\begin{array}{llll}\text { FALA }^{1} & >\text { ESCRITA }^{1} & >\text { ESCRITA }^{2} & >\text { FALA }^{2} \\ \text { inovadora } & \text { conservadora } & \text { conservadora } & \text { conservadora } \\ \text { inovadora } & & & \end{array}$

Um dos aspectos em que esse processo se evidencia poderia ser exemplificado pelo parâmetro do sujeito nulo, isto é, pela possibilidade de haver ou não elemento lexical na posição de sujeito em sentenças do português. Referindo pesquisa de Duarte (1996), Kato mostra que,na gramática do $\mathrm{PE}$, predominava o sujeito vazio, padrão assumido pelo $\mathrm{PB}$ falado e escrito até o fim do séculoXIX. Na virada do século XX, no entanto, o PB falado começou a apresentar um padrão diferente, preenchendo sujeitos por formas pronominais, inclusive em situação de coordenação de sentenças com mesmo sujeito, conforme Kato (1999, p. 205) ilustra em (1), (2) e (3):

(1) Hoje ø gostava de ser magistrado, porque ø estou convencido que ø talvez evitasse mais injustiças como magistrado do que as que $\emptyset$ possoevitar como advogado. (PE) 
(2) ø Falei ontem com seu tenente-coroné, e ele disse-me que ø havia de vir com Sinhá Perpétua e com Sinhá moça Rosinha.(PB - peça teatral séc.XIX)

(3) Quando ela acordou, ela estava em Hong Kong (PB - peça teatral séc. XX)

Desse modo, numa síntese da leitura dos argumentos oferecidos pela autora, pode-se dizer que, em contexto familiar, o falante brasileiro, mesmo o letrado, ofereceráà aquisição da gramática pela criança dados com preenchimento de sujeito. Ao chegar à escola, no entanto, a criança deverá aprender que,pelo menos na escrita mais “cuidada”, os sujeitos devem ser nulos.

Esse tipo de situação, nas quais as mudanças sofridas pelo PB não se refletem na gramática da escrita aprendida na escola, pode ser observado em outros fenômenos como o clítico nulo, a perda da ordem $\mathrm{X} /$ verbo/sujeito e as relativas padrão.

Sobre este último, de especial interesse para este artigo,Kato(1999)correlaciona o fenômeno da topicalização, típico da fala, ao emprego de estratégias não padrão de sentenças relativas.

No português, o indivíduo dispõe de três estratégias para relativização de constituintes:

(4) a. O vestido de que estou falando é de grife. (padrão)

b. $\mathrm{O}$ vestido que estou falando é de grife. (cortadora)

c. $\mathrm{O}$ vestido que estou falando dele é de grife. (copiadora)

Em (4)a, ilustra-se a forma como a tradição gramatical descreve/prescreve o uso de pronome relativo acompanhado da 
preposição exigida pela regência do verbo falar. É a forma predominante no português europeu (VAREJÃO, 2006) e é a estratégia ensinada nas escolas brasileiras como "a correta". Em b, exibe-se a estratégia cortadora, ou seja, aquela em que a preposição não aparece na oração relativa/adjetiva. Essa é uma estratégia de largo emprego na fala brasileira em qualquer nível de formalidade e já ocupa espaço considerável em textos de circulação pública, como artigos e reportagens (GOUVÊA, mimı'eo). Sua presença em textos escritos mais monitorados é evidência da "neutralidade" dessa estratégia quanto ao grau de avaliação dos letrados em face das normas de uso. Ao contrário, a sentença exibida em c exemplifica a estratégia copiadora, na qual um pronome ocupa a posição original do constituinte relativizado. Essa estratégia sofre estigma entre os escolarizados e, portanto, é combatida pela escola e evitada pelo letrado. Não se garante, no entanto, que seu emprego esteja descartado da fala escolarizada, como se vê na seguinte frase colhida na fala de um jornalista/apresentador de programa televisivo: "no próximo bloco, vocês vão conhecer Max, o cara que o Eduardo Martins roubou a face dele" (Programa Papo de segunda, exibido em 19 set. 2017).

Na base da variação de emprego dessas estratégias, segundo Kato (1999), haveria "parentesco" entre sentenças como o menino,o pai dele esteve aqui (topicalização deo menino), o menino que o pai dele esteve aqui (relativa copiadora) e o menino que o pai esteve aqui(cortadora). Em qualquer das estratégias não padrão, a fala estaria apresentando formas variantes (estruturas de tópico) que alimentam outras formas variantes (relativas cortadoras e copiadoras), num processo que pode 
chegar à escrita. Restaria indagar sobre com que grau de eficácia a escola consegue "bloquear" o emprego das variantes da fala na escrita. Segundo os resultados de Correa (1998), pessoas altamente letradas produzem relativas cortadoras em textos escritos.

Ainda a respeito dessas diferenças de usos,Duarte \& Serra (2015) fazem apropriada distinção entre "gramática" e "adequação linguística". Comparando um rap brasileiro a um lusitano, gênero musical de perfil popular e de forte apoio na modalidade falada da língua, as autoras mapeiam usos morfossintáticos distintos nas duas letras. Enquanto o rap lusitano exibe emprego de verbo haver, de clíticos acusativos e de verbos no pretérito-mais-que-perfeito, por exemplo, o brasileiro apresenta formas de concordância não redundante e emprego de pronomes nominativos em função acusativa. As autoras se baseiam nessa comparação para advogar favoravelmente à tese de que os usos exibidos na canção lusitana independem do grau de informalidade do discurso, pois o rap lusitano (exemplo de registro informal) traria, naturalmente, as marcas da gramática vernacular europeia. O rap brasileiro, nas mesmas condições de contexto, exemplificaria a naturalidade de nossa gramática da fala, já distanciada, em alguns aspectos, da lusitana. Duarte \& Serra (2015) defendemnão haver relação direta entre "informalidade" e gramática vernacular, discutindo que há pelo menos duas gramáticas às quais os brasileiros escolarizados têm acesso: a que se aproxima dos usos letrados e, portanto, da gramática lusitana, e a que se identifica com a gramática brasileira vernacular. Note-se, vale repetir, que o grau de letramento condiciona o acesso àqueles usos que refletem o português europeu porque o ensino de 
regras de escrita, no Brasil, é decalcado predominantemente nas descrições do português europeu literário, ou seja, nas descrições e prescrições das gramáticas normativas de Cunha, Lima, Bechara, entre outros, que se ancoram nos usos lusitanos. A questão, portanto, aponta para o fato de que, entre os brasileiros, a "adequação" da escolha entre variantes de gramáticas distintas (p. ex.: encontrei ele/encontrei-o; o livro de que eu falo/ o livro que eu falo/o livro que eu falo dele) só está ao alcance de indivíduos escolarizados que aprenderam a variedade mais próxima da lusitana, quer seja: a norma gramatical ensinada nas escolas (mas nem sempre aprendida em sua integralidade).

\section{Fala e escrita: da dicotomia ao contínuo}

Um olhar sobre o processo histórico por que passam as abordagens científicas acerca dessas modalidades de uso da língua pode contribuirna busca de respostas às questões em torno do papel destinado ao oral na sala de aula de português.

Ao mapear a evolução das tendências de tratamento das noções de fala e escrita, Marcuschi (2010, p. 27-34) apresenta um percurso que parte da dicotomia mais estritae chega à atual concepção de contínuo, ecoando a proposta de contínuos de variação, nos termos de BortoniRicardo (2004). Segundo o linguista, os primeiros trabalhos a refletir sobre a questão opunham fala e escrita, tendo como pressuposta a concepção de língua como código. Nessa perspectiva, dois blocos de propriedades tipificariam essas modalidades: de um lado a fala, concebida como realização contextualizada, dependente, implícita, 
redundante, não planejada, não normatizada, fragmentária; de outro a escrita, referida como produto linguístico descontextualizado, autônomo, explícito, condensado, planejado, preciso, normatizado e completo. Tal concepção dicotômica constitui, ainda hoje, modelo muito difundido em materiais didáticos e, como aponta Marcuschi (2010), responde pela inconveniente representação da fala como o lugar do caos gramatical e do "erro", reservando à escrita o lugar da unidade e da correção pacificada pela norma. Uma vez tradicionalmente concebido o estudo da língua como ensino/aprendizagem de regras gramaticais, é fácil perceber a razão pela qual a fala fica excluída dos conteúdos válidos no currículo escolar, inclusive na formação de professores.Concepções mais contemporâneas avançam para além da polarização e duasdelas merecem destaque pelo que podem oferecer ao campo pedagógico: as perspectivas variacionista e dialógica.

Ainda consoante Marcuschi (2010), a perspectiva variacionista procura superar as distinções estanques em busca de regularidades e variações de usos - motivadas por fatores linguísticos e sociais - em ambas as modalidades. À medida que o interesse do campo é extrair dos usos escritos e faladosregras padrão e não padrão que presidem às escolhas dos indivíduos em suas interações verbais, essa perspectiva traz a vantagem de possibilitar desconstruir a ideia de que a escrita representa o padrão e oferece à fala um tratamento adequado enquanto manifestação da língua em uso, como argumenta Marcuschi. Sendo assim, o variacionismopode oferecer subsídios mais adequados à abordagem do oral e do escrito no âmbito pedagógico. Uma crítica ao modelo, entretanto, aponta sua centralidade no produto, não 
oferecendo instrumentos para investigar os aspectos que recobrem a interação como processo. Essa dificuldade pode, no entanto, ser recoberta pela abordagem dialógica, cuja concepção de língua como processo interativo permite que tanto fala quanto escrita se definam por sua naturezadialógica, interacional, situada, coerente, dinâmica e orientada por usos estratégicos. Ainda na avaliação do referido linguista, o modelo traz a vantagem de oferecer mais instrumentos para a abordagem do oral, embora não alcanceexplicar e descrever fenômenos de natureza sintática, fonológica, e mesmo de produção e leitura de textos, impossibilitando a observação do processo de produção de sentidos, por exemplo.

Além disso, se parece clara a dificuldade na adoção de um modelo teórico único para abordagem do tema, ainda é preciso levar em conta os gêneros textuais que dão suporte aos textos. Marcuschi postula que "as diferenças entre fala e escrita se dão dentro de um continuum tipológico das práticas sociais e de produção textual" (MARCUSCHI, 2010, p. 37), estando ambos os domínios (fala e escrita) mais ou menos aproximados a partir de dois aspectos gradualmente observáveis: a linha dos gêneros textuais e a linha das características prototípicas de cada uma das modalidades. Considerada a gradação, os traços é que vão definir o lugar dos gêneros no contínuo.Como ilustração, observem-se os gêneros carta pessoal e relatório técnico. Embora ambos compartilhem o traço [+ escrita], a carta pessoal ocupa um extremo da escala que a aproxima do traço [+ fala], ao passo que o relatório técnico situa-se no outro extremo, sendo marcado pelo traço [+ escrita]. Claro está que não se trata de mera oposição, mas de observância às 
diferenças entre modo, contexto de produção e domínio discursivo que engendram opções/estratégias textuais e linguísticas diversas, mais ou menos aproximadas do que, prototipicamente, caracteriza fala e escrita. Desse modo, na produção e recepção de textos, estão em foco conhecimentos que certamente incluem as regras da gramática, mas extrapolam seu território e atingem as fronteiras do discurso, da cognição, da interação e dos gêneros textuais falados e escritos dispostos em escala gradual. Nesse sentido, como argumenta AraújoChiuchi (2011), não havendo modalidade "pura", a escrita apresenta aspectos que se originariam na gramática da fala, dado observável, inclusive, no emprego de uma pontuação marcadapela prosódia.

Evidências dessa interação podem ser encontradas nas retextualizações aqui analisadas, como se verá na seção de análise dos resultados.

\section{Processo de retextualização e metodologia da proposta de atividade didática}

As interações cotidianas envolvem processos de retextualização tão naturais quanto imperceptíveis à consciência. Relatar o conteúdo de uma aula a um colega, resumir a fala de um conferencista em breves anotações,escrever uma ata de reunião e anotar os fatos relatados por um queixoso ao serviço de atendimento ao cliente de uma loja, por exemplo, são eventos cotidianos de retextualização. Para realizá-los, os indivíduos fazem operações que em alguma medida interferem na forma e no conteúdo da informação original. Pressuposta a qualquer 
atividade dessa natureza, inicialmente, é a compreensão do texto baseque irá conferir maior ou menor fidedignidade à informação retextualizada. Além disso, como um processo sociointeracional, semelhante a qualquer outra ação discursiva, a intencionalidadedo retextualizador e o veículo a que se destina também interferemna forma e no conteúdo do produto final. Exemplo evidente dessa interferência é a opção pelo ajuste de uma concordância verbal ou do uso do SIC, por exemplo, na reelaboração de uma entrevista oral para veículo impresso.

Tratando-se de fala para escrita, modalidades linguísticas não dicotômicas, mas que guardam semelhanças e diferenças entre si, Marcuschi (2010, p. 77-86) afirma que a retextualização pode envolver até 9operações específicas, a saber:

$\mathbf{1}^{\mathrm{a}}$ - operação: eliminação de marcas estritamente interacionais, hesitações e partes de palavras;

$2^{\text {a }}$ operação: introdução da pontuação com base na intuição fornecida pela entoação das falas;

$3^{\underline{a}}$ operação: retirada de repetições, reduplicações e redundâncias, paráfrases e pronomes egóticos;

$4^{\text {a }}$ operação: introdução da paragrafação e pontuação detalhada sem modificação da ordem dos tópicos discursivos; $5^{\text {a }}$ operação: introdução de marcas metalinguísticas para referenciação de ações e verbalização de processos expressos por dêiticos;

6 a operação: reconstrução das estruturas truncadas, concordâncias, reordenação sintática, encadeamentos;

$7^{\mathfrak{a}}$ operação: tratamento estilístico com seleção de novas estruturas sintáticas e novas opções léxicas;

8 aperação: reordenação tópica do texto e reorganização da sequência argumentativa;

9 a operação: agrupamento de argumentos condensando as ideias. 
A tarefa didática que se relata possibilitou a observação do emprego de algumas dessas operações, mas este artigo se atém, basicamente, aos processos envolvidos nas operações 6 e 7. A primeira, por permitir focalizar o fenômeno morfossintático da relativização; a segunda, por trazer evidências acerca do grau de monitoração no processamento da escrita.

\section{Descrição da tarefa e discussão dos resultados}

Desenvolvida com 40 calouros do curso de Comunicação Social de uma instituição de ensino localizada no município do Rio de Janeiro, a proposta tevecomo objetivo ensejar reflexões sobre fala e escrita dentro do conteúdo programático variação linguística, momento em que se discutiram,na disciplina Língua Portuguesa, as definições de normaculta, norma padrão e outras normas, bem como o conceito de variação estilística (registro).Com intuito de promover a consciência de que os usos linguísticos refletem escolhas condicionadas por contextos internos e externos à língua, foram apresentadas algumas variantes morfossintáticas investigadas em trabalhos sociolinguísticos, como, por exemplo, o quadro pronominal do $\mathrm{PB}$, as concordâncias e as estratégias de relativização. Em razão das especificidades do curso, a teoriafoi resumidamente apresentada e discutida a partir da projeção detranscrições de fala e retextualizações escritas em diferentes normas e registros, que também serviram para firmar as diferenças entre a passagem do sonoro para o gráfico (transcodificação ou transcrição) e a passagem do gráfico para o escrito (retextualização ou adaptação). 
Nessa etapa, foram apresentados símbolosde transcrição mais comuns, conforme Marcuschi (1986). Em seguida,solicitou-se a tarefa, concebida em quatro blocos de atividades: (i) ouvir/ver uma entrevista oral de livre escolha;(ii) transcrever cerca de 10 minutos;(iii) retextualizar para uma publicação escrita a ser definida pela dupla de trabalho, mantendo ou não o gênero entrevista, no registro semiformal ou formal, e (iv) fazer observações sobre aspectos da variação linguística observada na fala dos entrevistados enas escolhas de escrita feitas pelos retextualizadores.

Para corroborar reflexões em direção ao campo pedagógico, após a tarefa concluída pelos estudantes, optou-se por coletar e controlar as ocorrências de sentenças relativas, consoante os fatores "grau de registro" (semiformal ou formal), "estratégia de relativização", "pronome relativo empregado" e "função sintática do relativo". Os dados foram submetidos ao programa estatístico GoldvarbX.

\section{Consciência sobre a variação}

Conforme a operação 7 estabelecida por Marcuschi e anteriormente mencionada, os fragmentos abaixo demonstram que os estudantes têm consciência sobre escolhas por estratégias gramaticais consideradas mais adequadas à escrita (semi)formal, conforme demonstra o quadro abaixo: 
Fragmento 1: Fala culta semiformal para escrita semiformal

\begin{tabular}{|c|c|}
\hline ENTREVISTA ORAL & ENTREVISTA ESCRITA \\
\hline $\begin{array}{l}\text { foi um milagre burnier...acho que foi um/a } \\
\text { gente encarou como um milagre assim... foi } \\
\text { como uma ... um renascimento da família toda } \\
\text { pra gente agrade/a gente não sabe NEM como } \\
\text { começar a agradecer quando a gente tava } \\
\text { uns...quinze minutos fora de: de campo grande } \\
\text { eu tava sentado eu meu filho mais velho } \\
\text { joaquim do meu lado...o benício do meu lado o } \\
\text { joaquim na minha frente a angélica as duas } \\
\text { babás e a evatava: brincando pelo avião....e aí: } \\
\text { o avião fez bum: mudou o barulho e deu uma } \\
\text { bundadinha assim de lado...aí: eu que gosto de } \\
\text { aviação olhei o piloto tava mexendo na: bomba } \\
\text { de combustível: eu olhei o painel vi que: um } \\
\text { motor tava apagado e tinha um motor só ... aí } \\
\text { comecei a trocar ideia com com o comandante } \\
\text { que foi...só posso agradecer ele: salvou a todos } \\
\text { nós...osmarêh... }\end{array}$ & $\begin{array}{l}\text { Foi como um milagre, um renascimento pra } \\
\text { família toda, Burnier. A gente não sabe nem } \\
\text { como começar a agradecer. Quando estávamos } \\
\text { - eu, Angélica, meus filhos e as duas babás - há } \\
\text { uns quinze minutos de Campo Grande, o avião } \\
\text { fez um barulho diferente e oscilou um pouco } \\
\text { para o lado. Eu olhei para o piloto, que estava } \\
\text { mexendo na bomba de combustível, e vi no } \\
\text { painel que um motor estava apagado. Então, } \\
\text { fui conversar com o Osmar, a quem eu só } \\
\text { posso agradecer, pois ele salvou a todos nós. }\end{array}$ \\
\hline
\end{tabular}

Como esperado, nesse fragmento é possível observarque as operações de eliminação de hesitações, de inserções e de um segmento descritivoreduziram o texto original de 141palavras faladaspara 89 palavras escritas.

Quanto ao registro, destacou-se que os retextualizadores informaram a decisão de"deixar a fala dos entrevistados um pouco mais formal, por isso a substituição do termo 'a gente' pela primeiro pessoa do plural em diversos momentos do texto.” Também revelaram a opção por evitar"o uso de gírias e palavras coloquiais, como no trecho da 
transcrição em que Luciano fala 'o avião fez bum: mudou o barulho e deu uma bundadinha assim de lado"'. Disso se extrai que,a partir dos mecanismos envolvidos na operação 7 descrita por Marcuschi (2010),é possível deduzir que os estudantes concebem que “maior formalidade" é condição decalcada na seleção lexical e em certas estruturas morfossintáticas associadas à escrita, conclusão que o processo de letramento permite elaborar de forma consciente. No fragmento 2 da mesma entrevista, isso fica mais evidente:

Fragmento 2: Fala culta semiformal para escrita semiformal

\begin{tabular}{|c|c|}
\hline ENTREVISTA ORAL & ENTREVISTA ESCRITA \\
\hline $\begin{array}{l}\text { Eu tava com muita dor nas costas muita } \\
\text { muitamuita mas eu sabia que eu não podia } \\
\text { esmorecer que eu tinha que eu tinha que } \\
\text { resolver aquilo até: ta todo mundo bem e a } \\
\text { angélica não sabia/a angélica achou que tinha } \\
\text { acontecido alguma coisa dentro porque ela } \\
\text { chorava muito ela não conseguia andar ela se } \\
\text { retorcia toda (angélica complementa) ela tava } \\
\text { muito nervosa e: as crianças tavam bem a eva } \\
\text { que chorava muito a gente achou que ela tinha } \\
\text { se machucado por dentro ela tava com uma } \\
\text { marca na lateralzinha aqui mas foi a babá que } \\
\text { apertou muito ela }\end{array}$ & $\begin{array}{l}\text { Eu estava com uma dor muito forte nas costas, } \\
\text { mas sabia que eu não podia fraquejar porque } \\
\text { eu tinha que resolver aquilo até todos estarem } \\
\text { bem. A Angélica, achando que alguma coisa } \\
\text { havia acontecido dentro do avião, estava } \\
\text { completamente nervosa - ela não conseguia } \\
\text { andar e se retorcia toda. A Eva chorava tanto } \\
\text { que achamos que ela tinha se machucado por } \\
\text { dentro. Depois, vimos que a marca na lateral do } \\
\text { corpo dela havia sido provocada pela babá que, } \\
\text { no susto, apertou muito a menina. }\end{array}$ \\
\hline
\end{tabular}

Considerando os dois fragmentos, podemos supor que, no nível lexical, as expressões "deu uma bundadinha" e "esmorecer"foram consideradas coloquiais, tendo sido substituídas por “oscilar' e "fraquejar".Do ponto de vista morfossintático, o pronome "a gente" foi mantido no primeiro fragmento, mas foi suprimido do segundo, sendo 
substituído por "[nós] vimos que”. Também se observa a supressão reiterada do pronome sujeito "eu" em consonância com a operação 3, que também pode ser interpretada como resultado das pressões de regras normativas da escola, segundo as quais a repetição do pronome sujeito deve ser evitada na escrita culta.O rearranjo de "ela tava com uma marca na lateralzinha aqui mas foi a babá que apertou muito ela” para "vimos que a marca na lateral do corpo dela havia sido provocada pela babá que, no susto, apertou muito a menina" pode revelar algumas concepções construídas ao longo da escolarização básica. A troca de "ter" por "haver" marcaria a passagem do registro informal para o (semi)formal. O diminutivo de "lateralzinha" pode ter sido eliminado em razão de, supostamente, representar marca de oralidade. É interessante notar, no entanto, que "apertou muito ela"foi adaptado para "apertou muito a menina". Como nãooptaram por "apertou-a muito", é possível supor que os retextualizadores, embora pretendessem conferir maior grau de formalidade para a adaptação para a entrevista escrita, não consideraram aplicável a regra de uso do pronome objeto "a", optando pela estratégia do emprego de sintagma nominal "a menina" em substituição a "ela".Essa escolha permite levantar a hipótese de que as diferentes estratégias de retomada anafórica de objeto, mostrando que as três opções da gramática do PB, distribuídas no contínuo estilístico (-a; ela; a menina), não implicam, para aqueles estudantes, as noções de "certo" e "errado", mas são recursos que a situação de uso pode legitimar em razão do contexto, no caso, o gênero textual entrevista (semi)formal, por exemplo. 
Os fragmentos acima evidenciam, portanto, que os estudantes monitoraram suas entrevistas escritas. No entanto, os resultados quantitativos sobre o emprego de estratégias de relativização indicam que, sobre certos fenômenos linguísticos, eles fazem escolhas dentro do limite da gramática aprendida (ou não) na escola. É o que se apresenta a seguir.

\section{Emprego de relativas preposicionadas na retextualização: resultados quantitativos 3}

O trabalho com retextualizações permitiu buscar evidências mais concretas sobre o fenômenoobservado e pôde oferecer contribuições para a compreensão da variação (contínuos de registro e relativização padrão e não padrão) em estreito diálogo com metodologias deensino de sintaxe.

Tendo em vista que as relativas preposicionadas têm baixa frequência,considerando a pouca produtividade dessa estrutura sintática nos textos, os dados quantitativos orientam melhor o desenho do quadro geral de emprego das variantes. A tabela imostra os resultados gerais para as três estratégias nos dois registros.

Tabela 1: Distribuição dos dados pelos tipos de relativização pelos registros

\begin{tabular}{|c|c|c|c|}
\hline Tipo de estratégia & Registro semiformal & Registro formal & Totais \\
\hline PADRÃO & $126(90 \%)$ & $21(84 \%)$ & $147(89,1 \%)$ \\
\hline
\end{tabular}

\footnotetext{
${ }^{3}$ Esta etapa da investigação contou com valiosa colaboração da bolsista de Iniciação Científica (CNPq) Gabriella Cristina da Silva, a quem agradeço pela coleta e codificação dos dados.
} 


\begin{tabular}{|c|c|c|c|}
\hline CORTADORA & $13(9,3 \%)$ & $3(12 \%)$ & $16(9,7 \%)$ \\
\hline COPIADORA & $1(0,7 \%)$ & $1(4 \%)$ & $2(1,2 \%)$ \\
\hline Totais & $140(84,8 \%)$ & $25(15,2 \%)$ & 165 dados \\
\hline
\end{tabular}

Das 165 sentenças relativas encontradas em 42 retextualizações que constituem a amostra, $147(89,1 \%)$ se apresentam na forma padrão. No entanto, deve-se ressaltar que a função sintática do termo relativizado interfere fortemente nesse resultado pró-padrão. No caso de serem relativizadas as funções de sujeito, objeto direto e predicativo, apenas duas variantes são esperadas: padrão ou copiadora. Como a copiadora sofre avaliação social negativa e é bloqueada pela escola, essa é uma estratégia evitada em textos mais monitorados, como os números da tabela 2 evidenciam:

Tabela 2: Distribuição das funções sintáticas pelos tipos de relativização

\begin{tabular}{|c|c|c|c|}
\hline Função sintática & Padrão & Cortadora & Copiadora \\
\hline Sujeito & $93(100 \%)$ & - & - \\
\hline Objeto direto & $34(100 \%)$ & - & - \\
\hline Predicativo & $6(100 \%)$ & - & - \\
\hline Objeto indireto & $1(100 \%)$ & - & - \\
\hline Adjunto adverbial & $9(52,9 \%)$ & $8(47,1 \%)$ & $1(16,7 \%)$ \\
\hline Complemento relativo & $2(33,3 \%)$ & $3(50 \%)$ & $1(50 \%)$ \\
\hline Adjunto adnominal & $1(50 \%)$ & - & - \\
\hline Comp. circunstancial & $1(50 \%)$ & $1(50 \%)$ & - \\
\hline Comp. nominal & - & $4(100 \%)$ & $2(1,2 \%)$ \\
\hline TOTAIS & $147(89,1 \%)$ & $16(9,7 \%)$ & - \\
\hline
\end{tabular}

Com exceção da única ocorrência de objeto indireto, transcrita em (5),todas as demais funções preposicionadas apresentaram emprego 
variável entre estratégias padrão e não padrão, incluindo duas ocorrências de copiadoras.

(5) ORIGINAL: aí comecei a trocar ideia com com o comandante que foi...só posso agradecer ele: salvou a todos nós...osmarêh...

RET.: Então, fui conversar com o Osmar, a quem eu só posso agradecer, pois ele salvou a todos nós.

Excluindo-se o caso acima, nas demais 17 ocorrências de funções preposicionadas, a presença de relativa cortadora vai ser preferida em 16 dados, seja em contexto semiformal ou formal, como se observa em (6) e (7), respectivamente:

(6) ORIGINAL: [Entrevistadora] e você gostaria de abrir algum show de alguma banda ou de algum cantor? [Entrevistada] gostaria... éh... racionais sou fã e roberto carlos

RET.: Entrevistadora: Gostaria de abrir um show de alguma banda ou cantor?

C: Sim, do "Racionais", que sou fã, e do Roberto Carlos.

(7) ORIGINAL: vai ser a primeira eleição depois dos movimentos de junho de 2013 e que, talvez, valha a pena acreditar em alguém que foge completamente a todas as tradições políticas que tem uma história (...)

RET.: vai ser a primeira eleição depois dos movimentos de junho de 2013 e que, talvez, valha a pena acreditar em alguém que foge completamente a todas as tradições políticas que tem uma história (...)

A tabela ainda revela que estratégia cortadora, observada em textos falados e escritos de indivíduos letrados (CORREA, 1998), é favorecida quando se relativiza adjunto adverbial. Também corrobora os resultados obtidos por Vale (2014), segundo os quais o indivíduo letrado (parcial ou completamente)parece oscilar entre escolhas por estruturas como as 
reveladas em (8); (9)e (10), frases extraídas do nosso corpus, que representa a escrita de indivíduos de letramento intermediário:

(8) ORIGINAL: e aí surgiu na semana que eu fiz a música... surgiu um concurso de samba de terreiro na portela...

RET.: Na semana que eu fiz a música, surgiu um concurso de samba de terreiro na Portela.

(9) ORIGINAL: fora isso... tinha uma bomba de gasolina melhoraram a praça e re/me... melhorara ainda mais conforme está né?

RET.: Fora isso tinha uma bomba de gasolina e também melhoraram a praça até o ponto em que ela se encontra agora.

(10) ORIGINAL: Então, Inês, eu queria começar a entrevista de uma forma bem leve. Queria saber de você o seguinte, uma coisa que eu sempre quis saber: numa partida de futebol entre Brasil e Alemanha, você iria torcer por quem?

RET.: Inês, quero começar a entrevista de maneira bem leve, então vou perguntar algo que eu sempre tive curiosidade: em uma partida de futebol entre Brasil e Alemanha, por quem você torceria?

(11) ORIGINAL:nesse disco mesmo teve frases que eu fiz na hora de gravar que eu mudei na hora assim ah não to gostando muito dessa frase acho que eu vou/teve também uma vez que eu nesse disco um um momento ali em que eu gravei duas opções... e depois escolhi a que eu gostei mais que eu achei que soou melhor

RET.:Nesse disco mesmo houve frases que não gostei muito e resolvi mudá-las na hora de gravar.

Finalmente, cabe ainda ressaltar a majoritária preferência pelo emprego do pronome QUE, frente aos demais, como a tabela 3 demonstra:

Tabela 3: Distribuição dos pronomes empregados pelos tipos de relativização

\begin{tabular}{|c|c|c|c|}
\hline Pronome Empregado & PADRÃO & CORTADORA & COPIADORA \\
\hline QUE & $135(89 \%)$ & $15(9,7 \%)$ & $2(1.3 \%)$ \\
\hline QUAL & $3(100 \%)$ & - & - \\
\hline CUJO & $1(100 \%)$ & - & - \\
\hline ONDE & $2(66,7 \%)$ & $1(33,3 \%)$ & - \\
\hline
\end{tabular}




\begin{tabular}{|l|l|l|l|}
\hline QUEM & $4(100 \%)$ & - & - \\
\hline
\end{tabular}

Não há surpresas nesses resultados. Como já indicado na literatura, o pronome CUJO foi empregado em apenas 1 ocorrência. Em lugar desse pronome, que exige habilidades conscientes para seu emprego,ocorreu estratégia de esquiva como a ilustrada em (12), que resultou numa copiadora:

(12) ORIGINAL: Agora tem o direito de resposta que eu espero que seja... garantida a manutenção, se alguém recorrer na suprema corte. RET.: Agora tem a lei do direito de resposta que eu espero que sua manutenção seja garantida se alguém recorrer na suprema corte.

Quanto ao emprego de ONDE, são raras as ocorrências de caráter multifuncional (DIAS, 1998), como em (13), porque tambémseu emprego também é forte alvo de coerção pelos professores.

(13) ORIGINAL: Éh... você sabe que o... caetano veloso escreveu um negócio muito interessante... dizendo que... pé tem o acento... agudo... e quando vai pro aumentativo... esse acento... desaparece onde na verdade você pode ler pezão ou pezão...

RET.: Você sabe que o Caetano Veloso escreveu um negócio muito interessante dizendo que pé tem o acento agudo, e quando vai para o aumentativo esse acento desaparece onde, na verdade, você lê pezão ou pesão.

Quanto ao pronome QUEM, prescrito pela norma gramatical como o relativizador de substantivos de traço semântico [+ humano], parece que passou de ter essa regra de uso flexibilizada pelos professores, pois é evidente o emprego majoritário de QUE mesmo no caso de o traço estar presente, como se vê em (14): 
(14) ORIGINAL: eu tenho até um pouco didi nervosismo em pensar isso que tipo que eu ganho mais dinheiro/que eu já ganhei mais dinheiro que talvez/talvez não provável que muitos escritores que eu admiro: ou autores que eu admiro: não ganham esse dinheiro neh? RET.: Sinto até um nervosismo em pensar que muitos escritores e atores que eu admiro não ganharam tanto dinheiro quanto eu.

\section{Conclusões}

O desenvolvimento do trabalho em sala de aula permitiu, entre outras coisas, observar que reflexões em torno da fala e da escrita são importantes para a construção da consciência linguística dos estudantes, um dos suportes do processo de letramento e de ampliação de repertório. Nesse sentido, a retextualização constitui técnica metodológica de alto grau de eficácia porque contribui para ampliar o repertório de estratégias de linguagem (incluindo as gramaticais) exigido, inclusive, pela escrita (semi)formal, um dos fins do processo de escolarização. Em razão do enfoque comparativo, ainda foi interessante construir, em diálogo com os estudantes, a noção que a fala não é caótica, mas simplesmente apresenta diferente modo de produção.

A proposta possibilitou ainda, em termos mais gerais, encontrar evidências de que,naabordagem didática de estruturas morfossintáticas marcadas pela variação sociolinguística, como é o caso a variável "estratégias de relativização", a aprendizagem da forma padrão, como observado nas relativas preposicionadas, precisa receber tratamento mais específico, pois elas pertenceriam a uma gramática distante da brasileira vernacular, aproximando-se de uma língua estrangeira (SILVA, 164). 
Por fim, confirma-se a importância de considerar, comoprática pedagógica, a heterogeneidade constitutiva das línguas naturais. No gradientede registro, osníveis deformalidade se apresentamemescala contínua,corroborando a tese de que as diferenças entre fala e escrita se dão dentro de um continuum tipológico das práticas sociais de interação por meio de textos verbais.

\section{Referências}

ARAÚJO-CHIUCHI, A. C. O uso de vírgulas: evidências da heterogeneidade da escrita. In: Revista Estudos Linguísticos, São Paulo, v. 40, n. 2, p. 488-497, maiago 2011.

BAGNO, M. Gramática, pra que te quero? Conhecimentos linguísticos nos livros didáticos de português. Curitiba: Aymará, 2010.

BRASIL. Ministério da Educação. Parâmetro Curricular Nacional de Códigos e Linguagens. Brasília, 1998.

BORTONI-RICARDO, S. Educação em língua materna: a Sociolinguística em sala de aula. São Paulo: Parábola, 2004.

CASTILHO, A. A língua falada no ensino de português. São Paulo: Contexto, 2003.

CORREA, V. R. Orações relativas: o que se sabe e o que se aprende no português do Brasil. Tese de Doutorado, IEL, UNICAMP, 1998.

DIAS, C. S. D. O valor multifuncional do pronome relativo onde. In: Estudos da linguagem: atualidades e paradoxo. Rio de Janeiro: ASSEL, 1998, p. 21-26.

DUARTE, M. E. L.; SERRA, C. R. Gramática(s), ensino de português e "adequação linguística”. Matraga. Rio de Janeiro, v.22, n.36, jan/jun. 2015.

GOUVÊA, L. H. M. Construções relativas na escrita padrão. (mimeo). [19--]. 
KATO, M. A. Aquisição e aprendizagem da língua materna: de um saber inconsciente para um saber metalinguístico. In: GRIMM CABRAL, L.; MORAIS, J. (Orgs.).Investigando a linguagem, Florianópolis, Ed. Mulheres, 1999, p. 201-213.

KOCH, I. Interferências da oralidade na aquisição da escrita. Trabalhos em Linguística Aplicada. Campinas, n. 30, jul. /dez. 1997.

MARCUSCHI, L. A. Análise da conversação. São Paulo: Ática, 1986.

. Da fala para a escrita:atividades de retextualização. São Paulo: Cortez, 2010 .

NEVES, M. H. M. Que gramática estudar na escola?: Norma e uso na língua portuguesa. São Paulo: Contexto, 2003.

ROCHA LIMA. Gramática normativa da língua portuguesa. 39. ed. Rio de Janeiro: José Olympio, 1972.

SILVA, H. S. Aprendizagem e uso das relativas convencionais. In: Revista Diadorim, Rio de Janeiro: UFRJ, v. 6, p. 165-180, 2009.

VALE, M. J. Q. Estratégias de relativização na fala de adultos maranhenses. Tese de doutorado, UFRJ, Rio de Janeiro, 2014.

VAREJÃO, F. Variação das estruturas de concordância verbal e das estratégias de relativização no português europeu popular. Tese de doutorado, UFRJ, Rio de Janeiro, 2006.

Recebido em 12/10/2017.

Aprovado em 22/12/2017. 